\title{
Web-based self-care management program of patients with type 2 diabetes mellitus
}

\author{
Angela $\mathrm{MM}^{1 *}$, Marie $\mathrm{BRG}^{2}$, Ela Shyr $\mathrm{EC}^{3}$, Tayor, Racquel ${ }^{4}$, Cruz ${ }^{5}$, Calvin $\mathrm{J}^{6}$, Leon $\mathrm{D}^{7}$, Josephine $\mathrm{M}^{8}$
}

\section{*Corresponding author:}

${ }^{1}$ Ms. Maraeh Angela Mancha, BSN, Research Coordinator, Clinical Research, Trauma Surgery, Surgery Department, Hamad General Hospital, Doha, Qatar.

Email: maraeh_21@yahoo.com ORCID

${ }^{2-8}$ Centro Escolar University, School of Nursing, Mendiola, Manila, Philippines

Information about the article:

Received: Jan. 17, 2019

Accepted: Feb. 20, 2019

Published online: Dec. 27, 2019

Publisher

Nepal Health Research Society, Bahundhara -6, Gokarnesowor Municipality, Kathmandu, Nepal eISSN 2382-5545, ISSN 2676-1343 (Print)

(C) The Author(s). 2019

Content licensing: CC BY 4.0

\begin{abstract}
Background

The purpose of the study is to determine the effectiveness of web-based self-care management program for type 2 diabetes mellitus through sharing evidenced-based information about Diabetes through the use of a web-based module.
\end{abstract}

\section{Materials and methods}

The study used the quasi-experimental pre and posttest design to determine the effectiveness of a web-based selfcare management program in the management of patients with type 2 Diabetes mellitus (DM). The study was conducted in three phases and acquired 30 purposively selected type 2 DM adult patients. The study used a webbased self-care management program that included basic information about Type 2 Diabetes mellitus using three designed modules specifically for diet, exercise and drug management.

\section{Results}

The patient status during the pre and post-intervention phase is an FBS reading of $152 \mathrm{mg} / \mathrm{dl}$ or diabetes stage to pre- diabetes stage (119 mg/dl), normal BMI (22), low risk for obesity WHR and barely satisfactory to satisfactory level of knowledge to diabetes and DM management. There is very significant difference $(\mathrm{p}=<000)$ in the pre and post FBS reading of patients and the level of knowledge to diabetes and DM management after the web based DSME while there is no significant difference in the BMI and WHR. There is very significant difference $(p=<000)$ in the RBS readings of the patients during the 1st, 2 nd and 3rd phases of the intervention of .web based DSME $(p=<000)$ post hoc analysis with Wilcoxon Signed Rank Test revealed that there is very significant difference $(p=<000)$ between groups.

\section{Conclusion}

The use of web-based self-care management program is effective in improving FBS/RBS and level of knowledge to diabetes and DM management of patients with type 2 diabetes mellitus but needed longer intervention to improve BMI and WHR .Nurses as part of the DSME group and as health educator may use technology in giving health education to patients to improve patients self-management to diabetes

\section{Keywords}

BMI, patient, type 2 Diabetes mellitus 